\title{
Proximal point algorithms for zero points of nonlinear operators
}

\author{
Yuan Qing ${ }^{1}$ and Sun Young Cho ${ }^{2^{*}}$
}

"Correspondence: ooly61@yahoo.co.kr

${ }^{2}$ Department of Mathematics, Gyeongsang National University, Jinju, 660-701, Korea Full list of author information is available at the end of the article

\begin{abstract}
A proximal point algorithm with double computational errors for treating zero points of accretive operators is investigated. Strong convergence theorems of zero points are established in a Banach space.
\end{abstract}

MSC: 47H05; 47H09; 47H10;65J15

Keywords: accretive operator; fixed point; nonexpansive mapping; proximal point algorithm; zero point

\section{Introduction}

In this paper, we are concerned with the problem of finding zero points of an operator $A: E \rightarrow 2^{E^{*}}$; that is, finding $x \in \operatorname{dom} A$ such that $0 \in A x$. The domain $\operatorname{dom} A$ of $A$ is defined by the set $\{x \in E: A x \neq 0\}$. Many important problems have reformulations which require finding zero points, for instance, evolution equations, complementarity problems, mini-max problems, variational inequalities and optimization problems; see [1-20] and the references therein. One of the most popular techniques for solving the inclusion problem goes back to the work of Browder [21]. One of the basic ideas in the case of a Hilbert space $H$ is reducing the above inclusion problem to a fixed point problem of the operator $R_{A}: H \rightarrow 2^{H}$ defined by $R_{A}=(I+A)^{-1}$, which is called the classical resolvent of $A$. If $A$ has some monotonicity conditions, the classical resolvent of $A$ is with full domain and firmly nonexpansive. Rockafellar introduced the algorithm $x_{n+1}=R_{A} x_{n}$ and call it the proximal point algorithm; for more detail, see [22] and the references therein. Regularization methods recently have been investigated for treating zero points of monotone operators; for [23-33] and the references therein. Methods for finding zero points of monotone mappings in the framework of Hilbert spaces are based on the good properties of the resolvent $R_{A}$, but these properties are not available in the framework of Banach spaces.

In this paper, we investigate a proximal point algorithm with double computational errors based on regularization ideas in the framework of Banach spaces. The organization of this paper is as follows. In Section 2, we provide some necessary preliminaries. In Section 3, strong convergence of the algorithm is obtained in a general Banach space. In Section 4 , an application is provided to support the main results.

\section{Preliminaries}

In what follows, we always assume that $E$ is Banach space with the dual $E^{*}$. Recall that a closed convex subset $C$ of $E$ is said to have normal structure if for each bounded closed

○2014 Qing and Cho; licensee Springer. This is an Open Access article distributed under the terms of the Creative Commons Attribution License (http://creativecommons.org/licenses/by/2.0), which permits unrestricted use, distribution, and reproduction in any medium, provided the original work is properly cited. 
convex subset $K$ of $C$ which contains at least two points, there exists an element $x$ of $K$ which is not a diametral point of $K$, i.e., $\sup \{\|x-y\|: y \in K\}<d(K)$, where $d(K)$ is the diameter of $K$. It is well known that a closed convex subset of uniformly convex Banach space has the normal structure and a compact convex subset of a Banach space has the normal structure; for more details, see [34] and the references therein.

Let $U_{E}=\{x \in E:\|x\|=1\}$. E is said to be smooth or said to be have a Gâteaux differentiable norm if the $\operatorname{limit}_{t \rightarrow 0} \frac{\|x+t y\|-\|x\|}{t}$ exists for each $x, y \in U_{E}$. $E$ is said to have a uniformly Gâteaux differentiable norm if for each $y \in U_{E}$, the limit is attained uniformly for all $x \in U_{E}$. $E$ is said to be uniformly smooth or said to have a uniformly Fréchet differentiable norm if the limit is attained uniformly for $x, y \in U_{E}$. Let $\langle\cdot, \cdot\rangle$ denote the pairing between $E$ and $E^{*}$. The normalized duality mapping $J: E \rightarrow 2^{E^{*}}$ is defined by

$$
J(x)=\left\{f \in E^{*}:\langle x, f\rangle=\|x\|^{2}=\|f\|^{2}\right\}
$$

for all $x \in E$. In the sequel, we use $j$ to denote the single-valued normalized duality mapping. It is known that if the norm of $E$ is uniformly Gâteaux differentiable, then the duality mapping $J$ is single-valued and uniformly norm to weak* continuous on each bounded subset of $E$.

Let $C$ be a nonempty closed convex subset of $E$. Let $T: C \rightarrow C$ be a mapping. In this paper, we use $F(T)$ to denote the set of fixed points of $T$. Recall that $T$ is said to be contractive if there exists a constant $\alpha \in(0,1)$ such that

$$
\|T x-T y\| \leq \alpha\|x-y\|, \quad \forall x, y \in C .
$$

For such a case, we also call $T$ an $\alpha$-contraction. $T$ is said to be nonexpansive if

$$
\|T x-T y\| \leq\|x-y\|, \quad \forall x, y \in C .
$$

Let $D$ be a nonempty subset of $C$. Let $Q: C \rightarrow D$. $Q$ is said to be a contraction if $Q^{2}=Q$; sunny if for each $x \in C$ and $t \in(0,1)$, we have $Q(t x+(1-t) Q x)=Q x$; sunny nonexpansive retraction if $Q$ is sunny, nonexpansive, and contraction. $K$ is said to be a nonexpansive retract of $C$ if there exists a nonexpansive retraction from $C$ onto $D$.

The following result, which was established in [34], describes a characterization of sunny nonexpansive retractions on a smooth Banach space.

Let $E$ be a smooth Banach space and $C$ be a nonempty subset of $E$. Let $Q: E \rightarrow C$ be a retraction and $j$ be the normalized duality mapping on $E$. Then the following are equivalent:

(1) $Q$ is sunny and nonexpansive;

(2) $\|Q x-Q y\|^{2} \leq\langle x-y, j(Q x-Q y)\rangle, \forall x, y \in E$;

(3) $\langle x-Q x, j(y-Q x)\rangle \leq 0, \forall x \in E, y \in C$.

Let $I$ denote the identity operator on $E$. An operator $A \subset E \times E$ with domain $D(A)=\{z \in$ $E: A z \neq \emptyset\}$ and range $R(A)=\bigcup\{A z: z \in D(A)\}$ is said to be accretive if for each $x_{i} \in D(A)$ and $y_{i} \in A x_{i}, i=1,2$, there exists $j\left(x_{1}-x_{2}\right) \in J\left(x_{1}-x_{2}\right)$ such that $\left\langle y_{1}-y_{2}, j\left(x_{1}-x_{2}\right)\right\rangle \geq 0$. An accretive operator $A$ is said to be $m$-accretive if $R(I+r A)=E$ for all $r>0$. In a real Hilbert space, an operator $A$ is $m$-accretive if and only if $A$ is maximal monotone. In this paper, we use $A^{-1}(0)$ to denote the set of zeros of $A$. For an accretive operator $A$, we can define a 
nonexpansive single-valued mapping $J_{r}: R(I+r A) \rightarrow D(A)$ by $J_{r}=(I+r A)^{-1}$ for each $r>0$, which is called the resolvent of $A$.

In order to prove our main results, we also need the following lemmas.

Lemma 2.1 [35] Let E be a Banach space, and $A$ an m-accretive operator. For $\lambda>0, \mu>0$, and $x \in E$, we have

$$
J_{\lambda} x=J_{\mu}\left(\frac{\mu}{\lambda} x+\left(1-\frac{\mu}{\lambda}\right) J_{\lambda} x\right)
$$

where $J_{\lambda}=(I+\lambda A)^{-1}$ and $J_{\mu}=(I+\mu A)^{-1}$.

Lemma 2.2 [36] Let $\left\{a_{n}\right\}$ be a sequence of nonnegative numbers satisfying the condition $a_{n+1} \leq\left(1-t_{n}\right) a_{n}+t_{n} b_{n}+c_{n}, \forall n \geq 0$, where $\left\{t_{n}\right\}$ is a number sequence in $(0,1)$ such that $\lim _{n \rightarrow \infty} t_{n}=0$ and $\sum_{n=0}^{\infty} t_{n}=\infty,\left\{b_{n}\right\}$ is a number sequence such that $\lim _{\sup _{n \rightarrow \infty}} b_{n} \leq 0$, and $\left\{c_{n}\right\}$ is a positive number sequence such that $\sum_{n=0}^{\infty} c_{n}<\infty$. Then $\lim _{n \rightarrow \infty} a_{n}=0$.

Lemma 2.3 [37] Let $\left\{x_{n}\right\}$ and $\left\{y_{n}\right\}$ be bounded sequences in a Banach space E, and $\left\{\beta_{n}\right\}$ be a sequence in $(0,1)$ with

$$
0<\liminf _{n \rightarrow \infty} \beta_{n} \leq \limsup _{n \rightarrow \infty} \beta_{n}<1 .
$$

Suppose that $x_{n+1}=\left(1-\beta_{n}\right) y_{n}+\beta_{n} x_{n}, \forall n \geq 1$ and

$$
\limsup _{n \rightarrow \infty}\left(\left\|y_{n+1}-y_{n}\right\|-\left\|x_{n+1}-x_{n}\right\|\right) \leq 0 .
$$

Then $\lim _{n \rightarrow \infty}\left\|y_{n}-x_{n}\right\|=0$.

Lemma 2.4 [31] Let E a real reflexive Banach space with the uniformly Gâteaux differentiable norm and the normal structure, and $C$ be a nonempty closed convex subset of $E$. Let $S: C \rightarrow C$ be a nonexpansive mapping with a fixed point, and $f: C \rightarrow C$ be a fixed contraction with the coefficient $\alpha \in(0,1)$. Let $\left\{x_{t}\right\}$ be a sequence generated by the following $x_{t}=t f x_{t}+(1-t) S x_{t}$, where $t \in(0,1)$. Then $\left\{x_{t}\right\}$ converges strongly as $t \rightarrow 0$ to a fixed point $x^{*}$ of $S$, which is the unique solution in $F(S)$ to the following variational inequality $\left\langle f\left(x^{*}-x^{*}\right), j\left(x^{*}-p\right)\right\rangle \geq 0, \forall p \in F(S)$.

\section{Main results}

Theorem 3.1 Let E be a real reflexive Banach space with the uniformly Gâteaux differentiable norm and $A$ be an m-accretive operators in $E$. Assume that $C:=\overline{D(A)}$ is convex and has the normal structure. Let $f: C \rightarrow C$ be a fixed $\alpha$-contraction. Let $\left\{\alpha_{n}\right\},\left\{\beta_{n}\right\},\left\{\gamma_{n}\right\}$, and $\left\{\delta_{n}\right\}$ be real number sequences in $(0,1)$ such that $\alpha_{n}+\beta_{n}+\gamma_{n}+\delta_{n}=1$. Let $Q_{C}$ be the sunny nonexpansive retraction from $E$ onto $C$ and $\left\{x_{n}\right\}$ be a sequence generated in the following manner:

$$
x_{0} \in C, \quad x_{n+1}=\alpha_{n} f\left(x_{n}\right)+\beta_{n} J_{r_{n}}\left(x_{n}+e_{n+1}\right)+\gamma_{n} x_{n}+\delta_{n} Q_{C}\left(g_{n}\right), \quad \forall n \geq 0,
$$

where $\left\{e_{n}\right\}$ is a sequence in $E,\left\{g_{n}\right\}$ is a bounded sequence in $E,\left\{r_{n}\right\}$ is a positive real numbers sequence, and $J_{r_{n}}=\left(I+r_{n} A\right)^{-1}$. Assume that $A^{-1}(0)$ is not empty and the above control sequences satisfy the following restrictions: 
(a) $\lim _{n \rightarrow \infty} \alpha_{n}=0$ and $\sum_{n=1}^{\infty} \alpha_{n}=\infty$;

(b) $0<\liminf _{n \rightarrow \infty} \gamma_{n} \leq \limsup _{n \rightarrow \infty} \gamma_{n}<1$;

(c) $\sum_{n=1}^{\infty}\left\|e_{n}\right\|<\infty$ and $\sum_{n=0}^{\infty} \delta_{n}<\infty$;

(d) $r_{n} \geq \mu$ for each $n \geq 1$ and $\lim _{n \rightarrow \infty}\left|r_{n}-r_{n+1}\right|=0$.

Then the sequence $\left\{x_{n}\right\}$ converges strongly to $\bar{x}$, which is the unique solution to the following variational inequality $\langle f(\bar{x})-\bar{x}, j(p-\bar{x})\rangle \leq 0, \forall p \in A^{-1}(0)$.

Proof Fixing $p \in A^{-1}(0)$, we find that

$$
\begin{aligned}
\left\|x_{1}-p\right\| \leq & \alpha_{0}\left\|f\left(x_{0}\right)-p\right\|+\beta_{0}\left\|J_{r_{0}}\left(x_{0}+e_{1}\right)-p\right\|+\gamma_{0}\left\|x_{0}-p\right\|+\delta_{0}\left\|Q_{C}\left(g_{0}\right)-p\right\| \\
\leq & \alpha_{0} \alpha\left\|x_{0}-p\right\|+\alpha_{0}\|f(p)-p\|+\beta_{0}\left\|x_{0}-p\right\|+\beta_{0}\left\|e_{1}\right\| \\
& +\gamma_{0}\left\|x_{0}-p\right\|+\delta_{0}\left\|g_{0}-p\right\| \\
\leq & \left(1-\alpha_{0}(1-\alpha)\right)\left\|x_{0}-p\right\|+\alpha_{0}\|f(p)-p\|+\left\|e_{1}\right\|+\delta_{0}\left\|g_{0}-p\right\| .
\end{aligned}
$$

Next, we prove that

$$
\left\|x_{n}-p\right\| \leq M_{1}+\sum_{i=1}^{n}\left\|e_{i}\right\|+\sum_{i=1}^{n-1} \delta_{i}\left\|g_{i}\right\|,
$$

where $M_{1}=\max \left\{\left\|x_{0}-p\right\|, \frac{\|f(p)-p\|}{1-\alpha}\right\}<\infty$. In view of (3.1), we find that (3.2) holds for $n=1$. We assume that the result holds for some $m$. Notice that

$$
\begin{aligned}
\left\|x_{m+1}-p\right\| \leq & \alpha_{m}\left\|f\left(x_{m}\right)-p\right\|+\beta_{n}\left\|J_{r_{m}}\left(x_{m}+e_{m+1}\right)-p\right\|+\gamma_{m}\left\|x_{m}-p\right\| \\
& +\delta_{m}\left\|Q_{C}\left(g_{m}\right)-p\right\| \\
\leq & \alpha_{m} \alpha\left\|x_{m}-p\right\|+\alpha_{m}\|f(p)-p\|+\beta_{m}\left\|x_{m}-p\right\|+\beta_{m}\left\|e_{m+1}\right\| \\
& \quad+\gamma_{m}\left\|x_{m}-p\right\|+\delta_{m}\left\|Q_{C}\left(g_{m}\right)-p\right\| \\
\leq & \left(1-\alpha_{m}(1-\alpha)\right)\left\|x_{m}-p\right\|+\alpha_{m}(1-\alpha) \frac{\|f(p)-p\|}{1-\alpha} \\
& +\left\|e_{m+1}\right\|+\delta_{m}\left\|g_{m}-p\right\| \\
\leq & M_{1}+\sum_{i=1}^{m+1}\left\|e_{i}\right\|+\sum_{i=1}^{m} \delta_{i}\left\|g_{i}\right\| .
\end{aligned}
$$

This shows that (3.2) holds. In view of the restriction (c), we find that the sequence $\left\{x_{n}\right\}$ is bounded. Put $y_{n}=J_{r_{n}}\left(x_{n}+e_{n+1}\right)$ and $z_{n}=\frac{x_{n+1}-\gamma_{n} x_{n}}{1-\gamma_{n}}$. Now, we compute $\left\|z_{n+1}-z_{n}\right\|$. Note that

$$
\begin{aligned}
z_{n+1}-z_{n}= & \frac{\alpha_{n+1}}{1-\gamma_{n+1}} f\left(x_{n+1}\right)+\frac{\beta_{n+1}}{1-\gamma_{n+1}} y_{n+1}+\frac{\delta_{n+1}}{1-\gamma_{n+1}} Q_{C}\left(g_{n+1}\right) \\
& -\frac{\alpha_{n}}{1-\gamma_{n}} f\left(x_{n}\right)-\frac{\beta_{n}}{1-\gamma_{n}} y_{n}-\frac{\delta_{n}}{1-\gamma_{n}} Q_{C}\left(g_{n}\right) \\
= & \frac{\alpha_{n+1}}{1-\gamma_{n+1}}\left(f\left(x_{n+1}\right)-y_{n+1}\right)+y_{n+1}+\frac{\delta_{n+1}}{1-\gamma_{n+1}}\left(Q_{C}\left(g_{n+1}\right)-y_{n+1}\right) \\
& -\frac{\alpha_{n}}{1-\gamma_{n}}\left(f\left(x_{n}\right)-y_{n}\right)-y_{n}-\frac{\delta_{n}}{1-\gamma_{n}}\left(Q_{C}\left(g_{n}\right)-y_{n}\right) .
\end{aligned}
$$


This yields

$$
\begin{aligned}
\left\|z_{n+1}-z_{n}\right\| \leq & \frac{\alpha_{n+1}}{1-\gamma_{n+1}}\left\|f\left(x_{n+1}\right)-y_{n+1}\right\|+\left\|y_{n+1}-y_{n}\right\|+\frac{\alpha_{n}}{1-\gamma_{n}}\left\|f\left(x_{n}\right)-y_{n}\right\| \\
& +\frac{\delta_{n+1}}{1-\gamma_{n+1}}\left\|Q_{C}\left(g_{n+1}\right)-y_{n+1}\right\|+\frac{\delta_{n}}{1-\gamma_{n}}\left\|Q_{C}\left(g_{n}\right)-y_{n}\right\| .
\end{aligned}
$$

Next, we estimate $\left\|y_{n+1}-y_{n}\right\|$. In view of Lemma 2.1, we find that

$$
\begin{aligned}
\| y_{n} & -y_{n+1} \| \\
& \leq\left\|\frac{r_{n}}{r_{n+1}}\left(x_{n}+e_{n+1}\right)+\left(1-\frac{r_{n}}{r_{n+1}}\right) J_{r_{n+1}}\left(x_{n}+e_{n+1}\right)-\left(x_{n+1}+e_{n+2}\right)\right\| \\
& =\left\|\frac{r_{n}}{r_{n+1}}\left(\left(x_{n}+e_{n+1}\right)-\left(x_{n+1}+e_{n+2}\right)\right)+\frac{r_{n+1}-r_{n}}{r_{n+1}}\left(J_{r_{n+1}}\left(x_{n}+e_{n+1}\right)-\left(x_{n+1}+e_{n+2}\right)\right)\right\| \\
& \leq\left\|x_{n}-x_{n+1}\right\|+\left\|e_{n+1}\right\|+\left\|e_{n+2}\right\|+\frac{M_{2}}{\mu}\left(r_{n+1}-r_{n}\right),
\end{aligned}
$$

where $M_{2}$ is an appropriate constant such that

$$
M_{2} \geq \sup _{n \geq 1}\left\{\left\|J_{r_{n+1}}\left(x_{n}+e_{n}\right)-\left(x_{n+1}+e_{n+1}\right)\right\|\right\} .
$$

Substituting (3.4) into (3.3), we arrive at

$$
\begin{aligned}
\left\|z_{n+1}-z_{n}\right\|-\left\|x_{n}-x_{n+1}\right\| & \\
\leq & \frac{\alpha_{n+1}}{1-\gamma_{n+1}}\left\|f\left(x_{n+1}\right)-y_{n+1}\right\|+\left\|e_{n+1}\right\|+\left\|e_{n+2}\right\|+\frac{M_{2}}{\mu}\left(r_{n+1}-r_{n}\right)+\frac{\alpha_{n}}{1-\gamma_{n}}\left\|f\left(x_{n}\right)-y_{n}\right\| \\
& +\frac{\delta_{n+1}}{1-\gamma_{n+1}}\left\|Q_{C}\left(g_{n+1}\right)-y_{n+1}\right\|+\frac{\delta_{n}}{1-\gamma_{n}}\left\|Q_{C}\left(g_{n}\right)-y_{n}\right\| .
\end{aligned}
$$

In view of the restrictions (a), (b), (c), and (d), we find that

$$
\limsup _{n \rightarrow \infty}\left(\left\|z_{n+1}-z_{n}\right\|-\left\|x_{n}-x_{n+1}\right\|\right) \leq 0 .
$$

It follows from Lemma 2.3 that $\lim _{n \rightarrow \infty}\left\|z_{n}-x_{n}\right\|=0$. It follows from the restriction (b) that

$$
\lim _{n \rightarrow \infty}\left\|x_{n+1}-x_{n}\right\|=0
$$

Notice that

$$
\begin{aligned}
\| x_{n}- & J_{r_{n}}\left(x_{n}+e_{n+1}\right) \| \\
\leq & \left\|x_{n}-x_{n+1}\right\|+\left\|x_{n+1}-J_{r_{n}}\left(x_{n}+e_{n+1}\right)\right\| \\
\leq & \left\|x_{n}-x_{n+1}\right\|+\alpha_{n}\left\|f\left(x_{n}\right)-J_{r_{n}}\left(x_{n}+e_{n+1}\right)\right\|+\gamma_{n}\left\|x_{n}-J_{r_{n}}\left(x_{n}+e_{n+1}\right)\right\| \\
& \quad+\delta_{n}\left\|Q_{C}\left(g_{n}\right)-J_{r_{n}}\left(x_{n}+e_{n+1}\right)\right\| .
\end{aligned}
$$


It follows that

$$
\begin{aligned}
& \left(1-\gamma_{n}\right)\left\|x_{n}-J_{r_{n}}\left(x_{n}+e_{n+1}\right)\right\| \\
& \quad \leq\left\|x_{n}-x_{n+1}\right\|+\alpha_{n}\left\|f\left(x_{n}\right)-J_{r_{n}}\left(x_{n}+e_{n+1}\right)\right\|+\delta_{n}\left\|Q_{C}\left(g_{n}\right)-J_{r_{n}}\left(x_{n}+e_{n+1}\right)\right\| .
\end{aligned}
$$

In view of the restrictions (a), (b), and (c), we find from (3.5) that

$$
\lim _{n \rightarrow \infty}\left\|x_{n}-J_{r_{n}}\left(x_{n}+e_{n+1}\right)\right\|=0
$$

Notice that

$$
\begin{aligned}
\left\|x_{n}-J_{r_{n}} x_{n}\right\| & \leq\left\|x_{n}-J_{r_{n}}\left(x_{n}+e_{n+1}\right)\right\|+\left\|J_{r_{n}}\left(x_{n}+e_{n+1}\right)-J_{r_{n}} x_{n}\right\| \\
& \leq\left\|x_{n}-J_{r_{n}}\left(x_{n}+e_{n+1}\right)\right\|+\left\|e_{n+1}\right\| .
\end{aligned}
$$

Since $\sum_{n=1}^{\infty}\left\|e_{n}\right\|<\infty$, we see from (3.6) that

$$
\lim _{n \rightarrow \infty}\left\|x_{n}-J_{r_{n}} x_{n}\right\|=0
$$

Take a fixed number $r$ such that $\epsilon>r>0$. In view of Lemma 2.1, we obtain

$$
\begin{aligned}
\left\|J_{r_{n}} x_{n}-J_{r} x_{n}\right\| & =\left\|J_{r}\left(\frac{r}{r_{n}} x_{n}+\left(1-\frac{r}{r_{n}}\right) J_{r_{n}} x_{n}\right)-J_{r} x_{n}\right\| \\
& \leq\left\|\left(1-\frac{r}{r_{n}}\right)\left(J_{r_{n}} x_{n}-x_{n}\right)\right\| \\
& \leq\left\|J_{r_{n}} x_{n}-x_{n}\right\| .
\end{aligned}
$$

Note that

$$
\left\|x_{n}-J_{r} x_{n}\right\| \leq\left\|x_{n}-J_{r_{n}} x_{n}\right\|+\left\|J_{r_{n}} x_{n}-J_{r} x_{n}\right\| \leq 2\left\|x_{n}-J_{r_{n}} x_{n}\right\| .
$$

This combines with (3.7), yielding

$$
\lim _{n \rightarrow \infty}\left\|x_{n}-J_{r} x_{n}\right\|=0 .
$$

Next, we claim that $\limsup _{n \rightarrow \infty}\left\langle f(\bar{x})-\bar{x}, j\left(x_{n}-\bar{x}\right)\right\rangle \leq 0$, where $\bar{x}=\lim _{t \rightarrow 0} z_{t}$, and $z_{t}$ solves the fixed point equation $z_{t}=t f\left(z_{t}\right)+(1-t) J_{r} z_{t}, \forall t \in(0,1)$, from which it follows that

$$
\left\|z_{t}-x_{n}\right\|=\left\|(1-t)\left(J_{r} z_{t}-x_{n}\right)+t\left(f\left(z_{t}\right)-x_{n}\right)\right\| .
$$

For any $t \in(0,1)$, we see that

$$
\begin{aligned}
\left\|z_{t}-x_{n}\right\|^{2}= & (1-t)\left\langle J_{r} z_{t}-x_{n}, j\left(z_{t}-x_{n}\right)\right\rangle+t\left\langle f\left(z_{t}\right)-x_{n}, j\left(z_{t}-x_{n}\right)\right\rangle \\
= & (1-t)\left(\left\langle J_{r} z_{t}-J_{r} x_{n}, j\left(z_{t}-x_{n}\right)\right\rangle+\left\langle J_{r} x_{n}-x_{n}, j\left(z_{t}-x_{n}\right)\right\rangle\right) \\
& +t\left\langle f\left(z_{t}\right)-z_{t}, j\left(z_{t}-x_{n}\right)\right\rangle+t\left\langle z_{t}-x_{n}, j\left(z_{t}-x_{n}\right)\right\rangle
\end{aligned}
$$




$$
\begin{aligned}
\leq & (1-t)\left(\left\|z_{t}-x_{n}\right\|^{2}+\left\|J_{r} x_{n}-x_{n}\right\|\left\|z_{t}-x_{n}\right\|\right) \\
& +t\left\langle f\left(z_{t}\right)-z_{t}, j\left(z_{t}-x_{n}\right)\right\rangle+t\left\|z_{t}-x_{n}\right\|^{2} \\
\leq & \left\|z_{t}-x_{n}\right\|^{2}+\left\|J_{r} x_{n}-x_{n}\right\|\left\|z_{t}-x_{n}\right\|+t\left|f\left(z_{t}\right)-z_{t}, j\left(z_{t}-x_{n}\right)\right\rangle .
\end{aligned}
$$

It follows that

$$
\left\langle z_{t}-f\left(z_{t}\right), j\left(z_{t}-x_{n}\right)\right\rangle \leq \frac{1}{t}\left\|J_{r} x_{n}-x_{n}\right\|\left\|z_{t}-x_{n}\right\|, \quad \forall t \in(0,1) .
$$

By virtue of (3.8), we find that

$$
\limsup _{n \rightarrow \infty}\left\langle z_{t}-f\left(z_{t}\right), j\left(z_{t}-x_{n}\right)\right\rangle \leq 0
$$

Since $z_{t} \rightarrow \bar{x}$, as $t \rightarrow 0$ and the fact that $j$ is strong to weak* uniformly continuous on bounded subsets of $E$, we see that

$$
\begin{aligned}
\left|\left\langle f(\bar{x})-\bar{x}, j\left(x_{n}-\bar{x}\right)\right\rangle-\left\langle z_{t}-f\left(z_{t}\right), j\left(z_{t}-x_{n}\right)\right\rangle\right| \\
\leq\left|\left\langle f(\bar{x})-\bar{x}, j\left(x_{n}-\bar{x}\right)\right\rangle-\left\langle f(\bar{x})-\bar{x}, j\left(x_{n}-z_{t}\right)\right\rangle\right| \\
\quad+\left|\left\{f(\bar{x})-\bar{x}, j\left(x_{n}-z_{t}\right)\right\rangle-\left\langle z_{t}-f\left(z_{t}\right), j\left(z_{t}-x_{n}\right)\right\rangle\right| \\
\leq\left|\left\langle f(\bar{x})-\bar{x}, j\left(x_{n}-\bar{x}\right)-j\left(x_{n}-z_{t}\right)\right\rangle\right|+\left|\left\langle f(\bar{x})-\bar{x}+z_{t}-f\left(z_{t}\right), J\left(x_{n}-z_{t}\right)\right\rangle\right| \\
\leq\|f(\bar{x})-\bar{x}\|\left\|j\left(x_{n}-\bar{x}\right)-j\left(x_{n}-z_{t}\right)\right\| \\
\quad+\left\|f(\bar{x})-\bar{x}+z_{t}-f\left(z_{t}\right)\right\|\left\|x_{n}-z_{t}\right\| \rightarrow 0, \quad \text { as } t \rightarrow 0 .
\end{aligned}
$$

Hence, for any $\epsilon>0$, there exists $\lambda>0$ such that $\forall t \in(0, \lambda)$ the following inequality holds:

$$
\left\langle f(\bar{x})-\bar{x}, j\left(x_{n}-\bar{x}\right)\right\rangle \leq\left\langle z_{t}-f\left(z_{t}\right), j\left(z_{t}-x_{n}\right)\right\rangle+\epsilon .
$$

This implies that

$$
\limsup _{n \rightarrow \infty}\left\langle f(\bar{x})-\bar{x}, j\left(x_{n}-\bar{x}\right)\right\rangle \leq \limsup _{n \rightarrow \infty}\left\langle z_{t}-f\left(z_{t}\right), j\left(z_{t}-x_{n}\right)\right\rangle+\epsilon .
$$

Since $\epsilon$ is arbitrary and (3.9), one finds that $\limsup _{n \rightarrow \infty}\left\langle f(\bar{x})-\bar{x}, j\left(x_{n}-\bar{x}\right)\right\rangle \leq 0$. This implies that

$$
\limsup _{n \rightarrow \infty}\left\langle f(\bar{x})-\bar{x}, j\left(x_{n+1}-\bar{x}\right)\right\rangle \leq 0 .
$$

Finally, we prove that $x_{n} \rightarrow \bar{x}$ as $n \rightarrow \infty$. Note that

$$
\begin{aligned}
\left\|x_{n+1}-\bar{x}\right\|^{2} \leq & \alpha_{n}\left\langle f\left(x_{n}\right)-\bar{x}, j\left(x_{n+1}-\bar{x}\right)\right\rangle+\beta_{n}\left\|y_{n}-\bar{x}\right\|\|\| x_{n+1}-\bar{x} \| \\
& +\gamma_{n}\left\|x_{n}-\bar{x}\right\|\left\|x_{n+1}-\bar{x}\right\|+\delta_{n}\left\|Q_{C}\left(g_{n}\right)-\bar{x}\right\|\left\|x_{n+1}-\bar{x}\right\| \\
\leq & \alpha_{n}\left\{f\left(x_{n}\right)-\bar{x}, j\left(x_{n+1}-\bar{x}\right)\right\rangle+\frac{\beta_{n}}{2}\left(\left\|y_{n}-\bar{x}\right\|^{2}+\left\|x_{n+1}-\bar{x}\right\|^{2}\right) \\
& +\frac{\gamma_{n}}{2}\left(\left\|x_{n}-\bar{x}\right\|^{2}+\left\|x_{n+1}-\bar{x}\right\|^{2}\right)+\frac{\delta_{n}}{2}\left(\left\|Q_{C}\left(g_{n}\right)-\bar{x}\right\|^{2}+\left\|x_{n+1}-\bar{x}\right\|^{2}\right) .
\end{aligned}
$$


Note that $\left\|y_{n}-\bar{x}\right\| \leq\left\|x_{n}-\bar{x}\right\|+\left\|e_{n+1}\right\|$. It follows that

$$
\begin{aligned}
\left\|x_{n+1}-\bar{x}\right\|^{2} \leq & 2 \alpha_{n}\left\langle f\left(x_{n}\right)-\bar{x}, j\left(x_{n+1}-\bar{x}\right)\right\rangle+\beta_{n}\left\|y_{n}-\bar{x}\right\|^{2} \\
& +\gamma_{n}\left\|x_{n}-\bar{x}\right\|^{2}+\delta_{n}\left\|Q_{C}\left(g_{n}\right)-\bar{x}\right\|^{2} \\
\leq & 2 \alpha_{n}\left\langle f\left(x_{n}\right)-\bar{x}, j\left(x_{n+1}-\bar{x}\right)\right\rangle+\left(1-\alpha_{n}\right)\left\|x_{n}-\bar{x}\right\|^{2}+v_{n}
\end{aligned}
$$

where $v_{n}=\left\|e_{n+1}\right\|\left(\left\|e_{n+1}\right\|+2\left\|x_{n}-\bar{x}\right\|\right)+\delta_{n}\left\|Q_{C}\left(g_{n}\right)-\bar{x}\right\|^{2}$. In view of the restriction (c), we find that $\sum_{n=1}^{\infty} v_{n}<\infty$. Let $\rho_{n}=\max \left\{\left\langle f\left(x_{n}\right)-\bar{x}, j\left(x_{n+1}-\bar{x}\right)\right\rangle, 0\right\}$. Next, we show that $\lim _{n \rightarrow \infty} \rho_{n}=0$. Indeed, from (3.10), for any give $\epsilon>0$, there exists a positive integer $n_{1}$ such that

$$
\left\langle f\left(x_{n}\right)-\bar{x}, j\left(x_{n+1}-\bar{x}\right)\right\rangle<\epsilon, \quad \forall n \geq n_{1} .
$$

This implies that $0 \leq \rho_{n}<\epsilon, \forall n \geq n_{1}$. Since $\epsilon>0$ is arbitrary, we see that $\lim _{n \rightarrow \infty} \rho_{n}=0$. In view of (3.11), we find that

$$
\left\|x_{n+1}-\bar{x}\right\|^{2} \leq\left(1-\alpha_{n}\right)\left\|x_{n}-\bar{x}\right\|^{2}+2 \alpha_{n} \rho_{n}+v_{n} .
$$

In view of Lemma 2.2, we find the desired conclusion immediately.

If the mapping $f$ maps any element in $C$ into a fixed element $u$ and $\delta_{n}=0$, then we have the following result.

Corollary 3.2 Let E be a real reflexive Banach space with the uniformly Gâteaux differentiable norm and $A$ be an m-accretive operators in E. Assume that $C:=\overline{D(A)}$ is convex and has the normal structure. Let $\left\{\alpha_{n}\right\},\left\{\beta_{n}\right\}$, and $\left\{\gamma_{n}\right\}$ be real number sequences in $(0,1)$ such that $\alpha_{n}+\beta_{n}+\gamma_{n}=1$. Let $\left\{x_{n}\right\}$ be a sequence generated in the following manner:

$$
x_{0} \in C, \quad x_{n+1}=\alpha_{n} u+\beta_{n} J_{r_{n}}\left(x_{n}+e_{n+1}\right)+\gamma_{n} x_{n}, \quad \forall n \geq 0,
$$

where $u$ is a fixed element in $C,\left\{e_{n}\right\}$ is a sequence in $E,\left\{g_{n}\right\}$ is a bounded sequence in $E,\left\{r_{n}\right\}$ is a positive real numbers sequence, and $J_{r_{n}}=\left(I+r_{n} A\right)^{-1}$. Assume that $A^{-1}(0)$ is not empty and the above control sequences satisfy the following restrictions:

(a) $\lim _{n \rightarrow \infty} \alpha_{n}=0$ and $\sum_{n=1}^{\infty} \alpha_{n}=\infty$;

(b) $0<\liminf _{n \rightarrow \infty} \gamma_{n} \leq \lim \sup _{n \rightarrow \infty} \gamma_{n}<1$;

(c) $\sum_{n=1}^{\infty}\left\|e_{n}\right\|<\infty$;

(d) $r_{n} \geq \mu$ for each $n \geq 1$ and $\lim _{n \rightarrow \infty}\left|r_{n}-r_{n+1}\right|=0$.

Then the sequence $\left\{x_{n}\right\}$ converges strongly to $\bar{x}$, which is the unique solution to the following variational inequality: $\langle u-\bar{x}, j(p-\bar{x})\rangle \leq 0, \forall p \in A^{-1}(0)$.

Remark 3.3 We remark here that the algorithm $(\Upsilon)$ is convergence under mild restrictions. However, it does not include the Halpern iterative algorithm as a special case because of the restriction (b). It is of interest to develop a different analysis technique for the algorithm without the restriction or under mild restrictions. 


\section{Applications}

In this section, we give an application of Theorem 3.1 in the framework of Hilbert spaces. For a proper lower semicontinuous convex function $w: H \rightarrow(-\infty, \infty]$, the subdifferential mapping $\partial w$ of $w$ is defined by

$$
\partial w(x)=\left\{x^{*} \in H: w(x)+\left\langle y-x, x^{*}\right\rangle \leq w(y), \forall y \in H\right\}, \quad \forall x \in H
$$

Rockafellar [38] proved that $\partial w$ is a maximal monotone operator. It is easy to verify that $0 \in \partial w(v)$ if and only if $w(v)=\min _{x \in H} g(x)$.

Theorem 4.1 Let $w: H \rightarrow(-\infty,+\infty]$ be a proper convex lower semicontinuous function such that $(\partial w)^{-1}(0)$ is not empty. Let $f: H \rightarrow H$ be a $\kappa$-contraction and let $\left\{x_{n}\right\}$ be a sequence in $H$ in the following process: $x_{0} \in H$ and

$$
\left\{\begin{array}{l}
y_{n}=\arg \min _{z \in H}\left\{w(z)+\frac{\left\|z-x_{n}-e_{n+1}\right\|^{2}}{2 r_{n}}\right\}, \\
x_{n+1}=\alpha_{n} f\left(x_{n}\right)+\beta_{n} y_{n}+\gamma_{n} x_{n}, \quad \forall n \geq 0,
\end{array}\right.
$$

where $\left\{e_{n}\right\}$ is a sequence in $H,\left\{g_{n}\right\}$ is a bounded sequence in $H$, and $\left\{r_{n}\right\}$ is a positive real numbers sequence. Assume that the above control sequences satisfy the restrictions (a), (b), (d), and $\sum_{n=1}^{\infty}\left\|e_{n}\right\|<\infty$. Then the sequence $\left\{x_{n}\right\}$ converges strongly to $\bar{x}$, which is the unique solution to the following variational inequality: $\langle f(\bar{x})-\bar{x}, j(p-\bar{x})\rangle \leq 0, \forall p \in(\partial w)^{-1}(0)$.

Proof Since $w: H \rightarrow(-\infty, \infty]$ is a proper convex and lower semicontinuous function, we see that subdifferential $\partial w$ of $w$ is maximal monotone. We note that

$$
y_{n}=\underset{z \in H}{\arg \min }\left\{w(z)+\frac{\left\|z-x_{n}-e_{n+1}\right\|^{2}}{2 r_{n}}\right\}
$$

is equivalent to $0 \in \partial w\left(y_{n}\right)+\frac{1}{r_{n}}\left(y_{n}-x_{n}-e_{n+1}\right)$. It follows that

$$
x_{n}+e_{n+1} \in y_{n}+r_{n} \partial w\left(y_{n}\right) \text {. }
$$

Putting $\delta_{n}=0$ in Theorem 3.1, we draw the desired conclusion from Theorem 3.1 immediately.

\section{Competing interests}

The authors declare that they have no competing interests.

Authors' contributions

Both authors contributed equally to this manuscript. Both authors read and approved the final manuscript.

\section{Author details}

'Department of Mathematics, Hangzhou Normal University, Hangzhou, 310036, China. ${ }^{2}$ Department of Mathematics, Gyeongsang National University, Jinju, 660-701, Korea. 


\section{References}

1. Kinderlehrer, D, Stampacchia, G: An Introduction to Variational Inequalities and Their Applications. Academic Press, New York (1980)

2. Zeidler, E: Nonlinear Functional Analysis and Its Applications, II/B. Nonlinear Monotone Operators. Springer, New York (1990)

3. Park, S: A review of the KKM theory on $\phi_{A}$-space or GFC-spaces. Adv. Fixed Point Theory 3, 355-382 (2013)

4. Qin, $X, C h o, Y J$, Kang, SM: Convergence theorems of common elements for equilibrium problems and fixed point problems in Banach spaces. J. Comput. Appl. Math. 225, 20-30 (2009)

5. Kim, JK: Strong convergence theorems by hybrid projection methods for equilibrium problems and fixed point problems of the asymptotically quasi- $\phi$-nonexpansive mappings. Fixed Point Theory Appl. 2011, Article ID 10 (2011)

6. Cho, SY, Kang, SM: Approximation of fixed points of pseudocontraction semigroups based on a viscosity iterative process. Appl. Math. Lett. 24, 224-228 (2011)

7. Abdel-Salam, HS, Al-Khaled, K: Variational iteration method for solving optimization problems. J. Math. Comput. Sci. 2, 1475-1497 (2012)

8. Wang, ZM, Lou, W: A new iterative algorithm of common solutions to quasi-variational inclusion and fixed point problems. J. Math. Comput. Sci. 3, 57-72 (2013)

9. Chen, JH: Iterations for equilibrium and fixed point problems. J. Nonlinear Funct. Anal. 2013, Article ID 4 (2013)

10. Noor, MA, Noor, Kl, Waseem, M: Decomposition method for solving system of linear equations. Eng. Math. Lett. 2 , 34-41 (2012)

11. Cho, SY: Hybrid projection algorithms for treating common fixed points of a family of demicontinuous pseudocontractions. Appl. Math. Lett. 25, 854-857 (2012)

12. Cho, SY: Iterative processes for common fixed points of two different families of mappings with applications. J. Glob. Optim. 57, 1429-1446 (2013)

13. He, RH: Coincidence theorem and existence theorems of solutions for a system of ky fan type minimax inequalities in FC-spaces. Adv. Fixed Point Theory 2, 47-57 (2012)

14. Wu, C: Wiener-Hope equations methods for generalized variational inequalities. J. Nonlinear Funct. Anal. 2013, Article ID 3 (2013)

15. Cho, SY, Kang, SM: Approximation of common solutions of variational inequalities via strict pseudocontractions. Acta Math. Sci. 32, 1607-1618 (2012)

16. Yuan, Q: Some results on asymptotically quasi- $\phi$-nonexpansive mappings in the intermediate sense. J. Fixed Point Theory 2012, Article ID 1 (2012)

17. Song, J, Chen, M: A modified Mann iteration for zero points of accretive operators. Fixed Point Theory Appl. 2013 Article ID 347 (2013)

18. Zegeye, $\mathrm{H}$, Shahzad, N: Strong convergence theorem for a common point of solution of variational inequality and fixed point problem. Adv. Fixed Point Theory 2, 374-397 (2012)

19. Qin, X, Su, Y: Strong convergence theorems for relatively nonexpansive mappings in a Banach space. Nonlinear Anal. 67, 1958-1965 (2007)

20. Wu, C, LV, S: Bregman projection methods for zeros of monotone operators. J. Fixed Point Theory 2013, Article ID 7 (2013)

21. Browder, FE: Existence and approximation of solutions of nonlinear variational inequalities. Proc. Natl. Acad. Sci. USA 56, 1080-1086 (1966)

22. Rockfellar, RT: Augmented Lagrangians and applications of the proximal point algorithm in convex programming Math. Oper. Res. 1, 97-116 (1976)

23. Cho, SY: Strong convergence of an iterative algorithm for sums of two monotone operators. J. Fixed Point Theory 2013, Article ID 6 (2013)

24. Qin, X, Su, Y: Approximation of a zero point of accretive operator in Banach spaces. J. Math. Anal. Appl. 329, 415-424 (2007)

25. Jung, JS: Some results on Rockafellar-type iterative algorithms for zeros of accretive operators. J. Inequal. Appl. 2013, Article ID 255 (2013)

26. Yang, S: Zero theorems of accretive operators in reflexive Banach spaces. J. Nonlinear Funct. Anal. 2013, Article ID 2 (2013)

27. Cho, SY, Kang, SM: Zero point theorems for $m$-accretive operators in a Banach space. Fixed Point Theory 13, 49-58 (2012)

28. Qing, Y, Cho, SY: A regularization algorithm for zero points of accretive operators. Fixed Point Theory Appl. 2013 Article ID 341 (2013)

29. Cho, SY, Li, W, Kang, SM: Convergence analysis of an iterative algorithm for monotone operators. J. Inequal. Appl. 2013, Article ID 199 (2013)

30. Ceng, LC, Khan, AR, Ansari, QH, Yao, JC: Strong convergence of composite iterative schemes for zeros of $m$-accretive operators in Banach spaces. Nonlinear Anal. 70, 1830-1840 (2009)

31. Qin, $X, C h o, S Y$, Wang, L: Iterative algorithms with errors for zero points of $m$-accretive operators. Fixed Point Theory Appl. 2013, Article ID 148 (2013)

32. Hao, Y: Zero theorems of accretive operators. Bull. Malays. Math. Soc. 34, 103-112 (2011)

33. Wu, C: Mann iteration for zero theorems of accretive operators. J. Fixed Point Theory 2013, Article ID 3 (2013)

34. Bruck, RE: Nonexpansive projections on subsets of Banach spaces. Pac. J. Math. 47, 341-355 (1973)

35. Barbu, V: Nonlinear Semigroups and Differential Equations in Banach Space. Noordhoff, Groningen (1976)

36. Liu, L: Ishikawa-type and Mann-type iterative processes with errors for constructing solutions of nonlinear equations involving m-accretive operators in Banach spaces. Nonlinear Anal. 34, 307-317 (1998)

37. Suzuki, T: Strong convergence of Krasnoselskii and Mann's type sequences for one-parameter nonexpansive semigroups without Bochne integrals. J. Math. Anal. Appl. 305, 227-239 (2005)

38. Rockafellar, RT: Characterization of the subdifferentials of convex functions. Pac. J. Math. 17, 497-510 (1966) 
10.1186/1687-1812-2014-42

Cite this article as: Qing and Cho: Proximal point algorithms for zero points of nonlinear operators. Fixed Point Theory and Applications 2014, 2014:42

Submit your manuscript to a SpringerOpen ${ }^{\circ}$ journal and benefit from:

- Convenient online submission

- Rigorous peer review

- Immediate publication on acceptance

Open access: articles freely available online

- High visibility within the field

- Retaining the copyright to your article

Submit your next manuscript at $\boldsymbol{s p r i n g e r o p e n . c o m ~}$ 